\section{Odontología de la Universidad Nacional Mayor de San Marcos: Pionera en el aprendizaje de la Microbiología bucal}

\author{
Dentistry of the National University of San Marcos: Pioneer in the \\ learning of Oral Microbiology
}

\section{EDITORIAL}

\author{
Hilda Moromi Nakata ${ }^{1, a}$ \\ 1 Facultad de Odontología. Universidad Nacional \\ Mayor de San Marcos. Lima, Perú. \\ a. Biólogo, Magister en Educación con mención en \\ Administración de la Educación Universitaria.
}

Correspondencia:

Hilda Moromi Nakata

Correo electrónico: hmoromin@unmsm.edu.pe Calle La Verbena 377. Santa Felicia. La Molina

Fecha de recepción: 22/05/17

Fecha de aceptación: 22/06/17
En el Perú la formación profesional del odontólogo se inició en la Universidad Nacional Mayor de San Marcos (UNMSM), en la Facultad de Odontología, allá por el 29 de octubre de 1943.

Siendo la perspectiva de la enseñanza de los microorganismos, históricamente llevado a cabo primero, por profesores Médicos Cirujanos, con su propia natural percepción profesional, mayormente clínica, sin mayor precisión de las noxas.

En la enseñanza por Asignaturas o disciplinar siempre estuvo el nombre de Bacteriología o Microbiología. Es así que en una reciente revisión ciberespacial de los Planes de Estudios de 27 Facultades y/o Escuelas, en el 82\% la asignatura se imparte en el segundo año de estudios; y en el 63\%, se enseña como Microbiología: oral, estomatológica, general, aplicada e Inmunología.
En las restantes Facultades y/o Escuelas no hay información disponible en el ciberespacio.

Entonces en la historia y evolución de la enseńanza de la microbiología, se puede distinguir dos etapas: una primera, disciplinar con la enseńanza primigeniamente por Profesores Médicos Cirujanos: Julio Morales Saravia, Alfonso Nicho Temoche, Manuel Quiroz Moscoso y José Huapaya Yaya, a los que se incorporaron los primeros Cirujanos Dentistas: Alfredo Márquez Oviedo y Jaime Dávila Nicho.

La segunda etapa, multidisciplinar, a partir de 1975, a instancias y visión del Profesor Alfonso Nicho Temoche: con inclusión de la asignatura de Microbiología Especial, considerando que las nosologías más importantes en la cavidad bucal: caries dental y periodontitis, están asociadas a los microorganismos, especialmente bacterias como: Streptococcus mutans, Porphyromonas gingivalis, Prevotella intermedia y Actinobacillus (Aggregatibacter actinomycetemcomitans), además de hongos como Candida albicans en un marco de concepción holística para confrontar la multifactorialidad causal de las enfermedades. En esta etapa se fue incorporando una larga lista de Profesionales Biólogos contratados (las primeras, Gladis Coral Hinostroza e Hilda Moromi Nakata) al igual que otros Cirujanos Dentistas. Desde su implementación a la fecha se ha actualizado permanente el contenido y la metodología del proceso de enseñanzaaprendizaje, incorporándose los seminarios, revisión de artículos científicos y los denominados formalmente "Trabajos de campo" en los sílabos, para incentivar a los estudiantes a integrar los conocimientos y puedan mostrar sus capacidades y habilidades desde una re- 
visión bibliográfica, la presentación de pequeños proyectos, la ejecución desde la toma de muestra, procesamiento en el laboratorio, presentación del informe con los resultados, discusión, conclusiones y exposición de los mismos. Los mejores trabajos son invitados para participar en las mesas clínicas de la Semana de la Facultad.

Paralelamente se comenzó a implementar y gestionar el Laboratorio de Microbiología para las investigaciones microbianas conexas a la Odontología; que con el tiempo se ha constituido en un referente para estudios microbianos y antimicrobianos para los alumnos de Tesis del Pre y Post Grado de nuestra Institución y otras universidades Me- tropolitanas y del interior del país. Muchas de estas investigaciones han sido difundidas en la Revista Odontología Sanmarquina y en otras, así como estudios de Fito antimicrobianos bucales, con resultados científicos y socialmente útiles, que se han difundido recientemente en publicación virtual ${ }^{1}$. Igualmente es destacable la publicación del Libro impreso Temas en Microbiología Oral (2013), de autoría de los actuales docentes: Donald Ramos Perfecto, Hilda Moromi Nakata y Elba Martínez Cadillo ${ }^{2}$.

Tal es la historia resumida de la enseñanza-aprendizaje de la Microbiología Bucal en el país.

\section{Referencias bibliográficas}

1. Moromi NH. Fito antimicrobianos en la salud bucal. [Internet] Lima (Perú); 2017 [citado el 22 de junio 2017]. Disponible en: http:// mrojas.perulactea.com/http:// mrojas.perulactea.com/wp-content/uploads/2017/04/HILDAFito-antimicrobiano_2017.pdf

2. Ramos PD, Moromi NH, Martínez CE. Temas de Microbiología Oral. Lima: CEPREDIM UNMSM; 2013. 